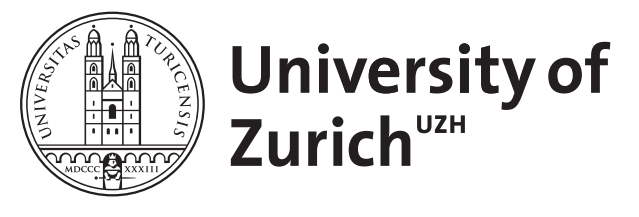

\title{
Truth without people?
}

Glock, Hans Johann

\begin{abstract}
There is a venerable tradition according to which the concept of truth is totally independent of human beings, their actions and beliefs, because truth consists in the correspondence of mindindependentpropositions to a mind-independent reality. For want of arespect. One way of doing so is relativism, the idea that whether a belief is true or false depends on the point of view of individuals or communities. A closely related position is a consensus theory of truth, according to which a belief is true if it is held by a (suitably qualified) group of people. In a similar vein, the pragmatist theory maintains that a true belief is one which it is expedient for us to accept.
\end{abstract}

DOI: https://doi.org/10.1017/S0031819100056667

Posted at the Zurich Open Repository and Archive, University of Zurich ZORA URL: https://doi.org/10.5167/uzh-56256

Journal Article

Published Version

Originally published at:

Glock, Hans Johann (1997). Truth without people? Philosophy, 72(279):85-104.

DOI: https://doi.org/10.1017/S0031819100056667 


\title{
Truth Without People?
}

\author{
HANS-JOHANN GLOCK
}

\section{Realism, Anthropocentrism and the Concept of Truth}

There is a venerable tradition according to which the concept of truth is totally independent of human beings, their actions and beliefs, because truth consists in the correspondence of mind-independent propositions to a mind-independent reality. For want of a better general term, I shall refer to this position as realism. There is an equally venerable, if less venerated, anti-realist tradition which questions the mind-independent nature of truth in some respect. One way of doing so is relativism, the idea that whether a belief is true or false depends on the point of view of individuals or communities. A closely related position is a consensus theory of truth, according to which a belief is true if it is held by a (suitably qualified) group of people. In a similar vein, the pragmatist theory maintains that a true belief is one which it is expedient for us to accept.

The realists would not deny that the truth or falsity of some of our beliefs is at least partly determined by what people say and do. This holds for those beliefs which are about human activities or their results. It is true that realists have often tended to play down the fact that most of our beliefs, including those of scientists in their laboratories, are not about the 'starry heavens above', but about human actions, or about objects and events which have been created or shaped by human activities. But this blindspot does not affect the cogency of their objections to the anti-realist positions. Relativism is wrong because to say that a belief is 'true for' a certain individual or community can amount to no more than saying that it is accepted by that individual or community. Both the consensus and the pragmatist theory ignore the fact that the truthvalue of our beliefs depends on how things are, not on how we say or think that they are, or on what we find expedient to believe.

Such points, suitably elaborated, rule out the above forms of anti-realism. But there are other ways of denying that truth is independent of human beings in absolutely every respect. One such approach is semantic anti-realism, which holds that propositions cannot be regarded as true or false unless it is possible in principle to verify or falsify them. This essay is concerned with yet 


\section{Hans-Johann Glock}

another challenge to the realist conception, one which has been less widely discussed, but is equally important. I shall refer to it as anthropocentrism, since it makes the notion of truth dependent on human activity (the point would apply equally to nonhuman intelligent creatures). One source of this position is pragmatism. Thus Davidson ascribes to Dewey the view that

nothing in the world, no object or event, would be true or false, if there were not thinking creatures.

Davidson defends this claim on the grounds that without creatures using sentences, nothing would count as a sentence, and hence the concept of truth would 'have no application'.' A similar idea is to be found in Wittgenstein.

'So you are saying that human agreement decides what is true and what is false?' It is what human beings say that is true and false; and they agree in the language they use (Philosophical Investigations, \$241).

In an unpublished manuscript (MS 124, pp. 212-3) he elaborated

So are you saying that human agreement determines //decides// what is true //correct// or false //incorrect? Correct or incorrect exist only in thinking, and hence in the expression of thoughts.

Realists like Russell have attacked Dewey's account of truth as being idealist, and Davidson has been charged with the same misdemeanour. Similarly, Wittgenstein has been accused of reducing truth to the consensus of a community. However, both Davidson and Wittgenstein explicitly disown the disreputable views ascribed to them. Prima facie, at least, they are right. Their claim is not that without people there would be no mountains, or that it is human consensus which decides whether it is true that there are mountains. Rather, they maintain that the notion of truth depends on, or in some way alludes to, the mental and linguistic activities of people.

In fact, one can distinguish two different claims in their position. One is that the existence of the concept of truth depends on the activities of 'thinking creatures' or people; the other that the concept of truth can only be explained by reference to such activities.

The first idea is that, unlike mountains, concepts are artefacts. It implies

(1) If there were no people, there would be no concept of truth.

1 'The Structure and Content of Truth', Fournal of Philosophy 87 (1990), pp. 279, 300. 
A possible rationale for (1) is conceptualism, the idea that a concept is a principle of classification which exists only as part of our activity of classification. If people did not classify things, e.g., into those which are radioactive and those which are not, the concept of radioactivity would not exist. By the same token, if there were no human beings, and if consequently no classifications were made at all, there would be no concepts whatsoever.

This claim is compatible with the fact that people use different words for drawing the distinction between being radioactive and not being radioactive. It is also compatible with the idea that properties, unlike concepts, exist independently of human beings: uranium has the property of being radioactive whether or not anybody so classifies it. Conceptualism is even compatible with the idea (denied by conceptual relativists) that our concepts must mirror such mind-independent properties. For that idea implies only that concepts which fail to mirror the purported properties of the world are incorrect, not that any concepts (correct or incorrect) exist without creatures classifying things.

Different versions of conceptualism disagree on whether the human activity to which concepts owe their existence is mental (acts of abstraction, or of the imagination) or linguistic (the ruleguided use of words). But in either version, conceptualism is controversial. One might protest that even if there were no creatures making classifications, there would be principles of classification according to which things could be classified if there were such creatures. However, the idea that concepts exist independently of people explaining justifying or correcting their classifications by reference to such principles presupposes that concepts are selfsubsistent entities. Since they are not material objects, they would have to be abstract entities that reside in a separate ontological realm beyond space and time.

To hold this view is to adopt a Platonist account of concepts. Accordingly, there is at least one qualification of the realist conception of truth which is not committed to anti-realist positions. To deny that concepts exist independently of human practice is not to condone relativism, idealism, or a pragmatist or consensus theory. Rather, it is to reject the Platonist claim that a general term like 'truth' refers to a self-subsistent abstract entity. Thus Wittgenstein would argue that this term expresses a concept not because it stands for something beyond space and time, but because there is a rule-guided practice of using it and its cognates, notably a practice of classifying statements into true and false. To use his famous analogy: what gives significance to the king in chess, and distinguishes it from a mere piece of wood, is not that it 


\section{Hans-Johann Glock}

is associated with an abstract entity, but that we have laid down rules for its use.

While this position may not be unassailable, it is far from absurd. Note, however, that it covers all concepts. If correct, it holds for the concept of a mountain no less than for the concepts of truth and of falsity. While

(2) If there were no people, there would be no mountains is false, on the conceptualist view

$\left(2^{\prime}\right)$ If there were no people, there would be no concept of a mountain

is correct. The question is whether there is anything about the concepts of truth and falsity which separates them from concepts like that of a mountain by introducing an additional dependency on human beings and their activities.

The second strand in anthropocentrism answers this question in the affirmative, on the grounds that the bearers of truth depend on people. In the next section, I reject the mentalist and nominalist conceptions of truth-bearers which would directly support that contention. We apply 'true' neither to mental episodes nor to sentences, but to what is or could be said. However, section III also rejects the Platonist view that truths are self-subsistent abstract entities. In the final section I argue that the result is not that there can be no truths without people (a thesis held by Rorty), but a more subtle anthropocentrism which links the concept of truth to the concept of a language. My ambition is not to provide conclusive arguments in favour of anthropocentrism. It is to show that there is a version of it which does not rest on implausible anti-realisms, but on subtle points in philosophical logic which deserve serious consideration.

\section{Unbearable Truth-Bearers: Mentalism and Nominalism}

It is uncontroversial that some concepts fit the anthropocentric view, namely those which classify exclusively human traits, or human activities and their results, e.g. the concept of bad manners. The general idea informing both Davidson and Wittgenstein is that it also holds of truth and falsity. A first stab at their position runs as follows

$\left(1^{\prime}\right)$ If there were no people, there would be no bearers of truth.

This raises the vexed question of what the bearers of truth and falsehood are, or, to put it in the formal mode, of what the terms 'true' and 'false' apply to. One traditional answer is mentalism. It 


\section{Truth Without People?}

attributes truth to ideas, beliefs, thoughts or judgements, and conceives of these as mental phenomena (states or episodes) which are the inalienable property of individuals. Another answer is Platonism, which treats a truth as an abstract rather than as a mental entity, a thought (Frege) or proposition (Moore) which exists in a realm beyond space and time, independently of whether human beings understand, believe or propound it.

The Platonist position implies realism, since it views truths as self-subsistent abstract entities. By contrast, mentalism entails the anthropocentric view: without intelligent creatures, there would not be the appropriate kind of mental episode (judgment, etc.) for 'true' to apply to. However, it seems that the mentalist position can easily be disposed of through objections that have been advanced by Platonists like Bolzano and Frege. Truths cannot be private phenomena in the minds of individuals, since truths can be communicated, and since one and the same truth can be believed or rejected by different individuals. It is fortunate for anthropocentrism, therefore, that there is another option, nominalism, which holds that what is true or false are neither mental nor abstract objects, but material ones, namely sentences.

Nominalism does not face the problems of mentalism, since its preferred truth-bearers are intersubjectively accessible. Often a nominalist account is simply stipulated as being the 'most convenient' one, or on the grounds that 'no confusion results' from adopting it. ${ }^{2}$ Such a stipulation may indeed be convenient for the purposes of its proponents, notably the construction of a formal semantics. But this cuts no ice in the present context. If the realist claims that the bearers of truth and falsity are language-independent, he cannot be refuted by pointing out that for constructive purposes in formal semantics it is convenient to apply 'is true' to sentences. After all, the debate between realism and anthropocentrism concerns the notion of truth as employed in ordinary, nonphilosophical discourse.

Tarski, the pioneer of the view that sentences are truth-bearers, was alive to this point. He claimed that his definition of truth did ' $n o t$ aim to specify the meaning of a familiar word used to denote a novel notion', but 'to catch hold of the actual meaning of the old notion'. But in that case the correct procedure is not to decide what the bearers of truth are by stipulation, but to examine

${ }^{2}$ See e.g., M. Dummett, Frege: Philosophy of Language (London: Duckworth, 1973), p. 444; A. Tarski, 'The Semantic Conception of Truth and the Foundations of Semantics', in H. Feigl and W. Sellars (eds), Readings in Philosophical Analysis (New York: Apple Century Crofts, 1949), p. 53 \& fn5; D. Davidson, Inquiries into Truth and Interpretation (Oxford University Press, 1984), pp. 43-45. 


\section{Hans-Johann Glock}

whether in ordinary discourse 'is true' is used as a predicate of sentences. I shall argue that it is not.

The claim that sentences are truth-bearers is ambiguous. It can mean either that a truth is a token-sentence, a particular utterance (sound) or inscription (marks on paper), or that it is a type-sentence, an acoustic or typographic pattern which can be instantiated by indefinitely many tokens. This second position was the one in effect held by Tarski. ${ }^{3}$ Since types are universals rather than particulars, this position is not strictly speaking nominalist. But that does not matter for us, since on either view, the anthropocentric claim $\left(1^{\prime}\right)$ holds true. Without speakers, there would be no tokensentences, and hence nothing for 'true' or 'false' to apply to. ( 1 ') equally holds if the bearers of truth and falsity are type-sentences. Without speakers, there would be no languages; and without languages, there would be no type-sentences. ${ }^{+}$

The idea that the bearers of truth and falsity are type-sentences runs into a difficulty pointed out by Strawson. ${ }^{5}$ Tokens of one and the same type can be used to express either a truth or a falsehood, depending on who uses it, where and when. This is not just the case with sentences involving indexicals ('You owe me ten dollars') but also with those involving most kinds of proper names ('The High Street is always busy').

${ }^{3}$ I ignore the complication that Tarski regarded sentences as 'classes of inscriptions of a similar form'. A type-sentence is not the same as the class of its tokens, since (i) the existence of tokens of that type is not guaranteed, (ii) there are properties of the tokens which the type must also possess, while the class cannot possess them: just like particular Union-Jacks, the Union-Jack type must be striped, which cannot be said of the class of Union Jacks.

' Ironically, in 'The Second Person', Midwest Studies in Philosophy XVII (1992), pp. 255-6, Davidson seems to suggest that the existence of a language does not depend on anybody speaking it, because it is an abstract object, unobservable and changeless. It is difficult to see how this can be squared with his claim in 'The Structure and Content of Truth' that the concept of truth would have no application in the absence of speakers, since nothing would count as a sentence. If languages do not depend on speakers, how could sentences? In my view, the Platonism of Davidson's Tarskian heritage and the anthropocentrism of his pragmatist inclinations are pulling him into opposite directions here. But what counts for our purposes is this. To maintain that languages can exist without speakers is even more problematic than holding that concepts do. It implies, for example, that languages cannot die out, and that, as regards existence, there is no difference between Spanish and Mohican.

${ }^{5}$ Logico-Linguistic Papers (London: Methuen, 1971), ch. 1; also S. Wolfram, Philosophical Logic: an Introduction (London: Routledge, 1989), ch. 2.4. 
In response to such difficulties, Quine and Davidson have modified Tarski's position. In effect, they claim that it is token-sentences or utterances which are true or false. 'What are best seen as primarily true or false are not [type-]sentences but events of utterance' ${ }^{6}{ }^{6}$ But this hard-headed nominalism also runs into a problem. There seems to be a logical difference between truths and tokensentences. That is, it makes sense to say things about token-sentences which it does not make sense to say about truths.

Token-sentences are particulars, acoustic events in the case of speech, visible material objects in the case of writing. They are located in space and time, and they have causes and effects. By contrast, truths or falsehoods are non-physical, atemporal and non-spatial. A spoken token-sentence can last for five seconds, be loud or high-pitched, but a truth cannot. A written token-sentence can be $10 \mathrm{~cm}$ long, consist of ink or chalk, and one can turn it upside down. But a truth cannot occupy any space or consist of any material stuff. One cannot destroy a truth by wiping a blackboard, or by setting fire to a piece of paper, and one cannot turn it upside down, except metaphorically.

However, there is a final option for the champions of sentences. To avoid absurdity, it may be conceded that the bearers of truth and falsity are types rather than tokens, that is, abstract entities which are proof against destruction by negligence or arson. To avoid the problem with Tarski's original suggestion, one can opt for type-sentences with a fixed rather than variable truth-value. Thus, in addition to suggesting that the bearers of truth are tokensentences, Quine also suggests that this role can be occupied by 'eternal sentences'. Eternal sentences are type-sentences-'repeatable linguistic forms' or 'sound patterns'-from which all indexical elements (pronouns, tenses, etc.), as well as all ambiguity and vagueness, have been removed, for example 'Bernard Ortcutt owes W. V. Quine ten U.S. dollars on July 151968 '?

6 W. V. Quine, Philosophy of Logic (Cambridge/Mass.: Harvard University Press, 1970), p. 13; see Pursuit of Truth (Cambridge/Mass.: Harvard University Press, 2. edn. 1992), pp. 78-9; see also D. Davidson, Inquiries into Truth and Interpretation (Oxford: Oxford University Press, 1984), pp. 33-4, 43-5, 58, 118. Davidson does not strictly speaking ascribe truths to speech acts, but his suggestion of relativizing the truth of a sentence to speakers, and times amounts to the same thing, since he treats speech acts as equivalent to ordered triples of sentences, speakers and times. To hold that a sentence is true 'as (potentially) spoken' by a person at a time is tantamount to saying that it is the utterance of the sentence by a person at a time which is true.

${ }^{7}$ Word and Object (Cambridge/Mass.: MIT Press, 1960), p. 191; Pursuit of Truth, p. 79. 


\section{Hans-Johann Glock}

Unfortunately, this suggestion also runs into difficulties. One problem is that the criteria of identity for truths, i.e. true beliefs, judgments, statements, claims, propositions, etc., are not the same as those for sentences even of the eternal variety. One and the same truth can be expressed not just by different token-sentences (e.g., different utterances of 'Snow is white'), but also by different typesentences, such as 'Snow is white' and 'Schnee ist weiß'.

Moreover, even type-sentences are logically distinct from truths and falsehoods. ${ }^{8}$ It makes sense to say things about the latter which it does not make sense to say about the former, and vice versa. What is true, that is, what is said, stated, asserted or claimed, can be in French, but unlike a type-sentence, it cannot be French. A type-sentence can contain six words or two commas, it can be elegant or clumsy, ungrammatical, hard to pronounce or badly punctuated, but none of this can be said of a truth. What is true, e.g. that the universe is unlimited yet finite, can be astonishing or remarkable. But sentences are remarkable in a completely different way, e.g. by containing eleven consecutive occurrences of the word 'had'.

Another difference arises with respect to intentional verbs. What is true or false, namely that $p$, is also what can be believed, expected, hoped, feared, etc. Yet, someone who is ignorant of English can believe the same as I do, for example that Atlantis never existed, but cannot be credited with believing the sentence 'Atlantis never existed'. Moreover, what A believes, namely that $p$, may also be what B expects, $\mathrm{C}$ fears and D hopes. And it definitely makes no sense to expect, fear or hope a sentence. This suggests that when we speak of believing a sentence, this is elliptical for believing what is said by it.

It might be objected that this last argument militates equally against ascribing truth or falsity to what is said: one can no more expect, fear or hope what is said than one can expect, fear or hope a sentence. However, although it would be odd to say 'I fear what she said', it is not odd to say 'What she said, namely that $p$, is what I fear'. By contrast, to say 'The sentence " $p$ " is what I fear' at best expresses a (peculiar) fear of an object (inscription) or event. What I fear (and what others believe, etc.) is that $p$. But 'that $p$ ' is not a sentence (it can only be transformed into one by adding 'is true'), nor does it designate a sentence; it reports what was said.

However, there are other responses to these arguments. First, it

${ }^{8}$ The following points are derived from Alan White's Truth (London and Basingstoke: Macmillan, 1970), pp. 7-18. But White does not distinguish between the claims that the bearers of truth are token-, type- and eternal sentences. 
might be objected that they hold of truths, but need not hold of the bearers of truth, which may therefore be sentences after all. But this response fails. The bearers of truth are what 'is true' applies to, and hence they are what is true. But what is true is a truth. If it is true that $p$, that $p$ is a truth. Consequently, what holds of truths also holds of the bearers of truth.

Next, the proponents of eternal sentences might insist that some truths simply are German or hard to pronounce, and so on. But if this insistence is to be more than a petitio principii, they need to explain what it means for a truth to be German, other than that the sentence which expresses it is German. Moreover, they would also have to insist that 'Snow is white' and 'Schnee ist weiß.' simply do not express the same truth. To phrase it in their terms, they are committed to the view that while both of these sentences are truths, they are not the same truth, since one of them is English and the other German. But that conclusion blatantly violates the way we individuate truths.

As Alan White has shown, reflection on our actual use of the terms 'true' and 'false' shows that we apply them not to the act of saying or writing something, nor to what is used to say or write it (roughly, a token of a type-sentence), but to what is said or written, e.g. that there are mountains or that uranium is radioactive, and also to what is made in saying it, e.g. an assertion or statement. In this respect, 'true' differs from a term like 'exaggerated'. Whereas the latter applies exclusively to sayings, the former applies also to naked that-clauses: it is true that there are mountains, but it is an exaggeration to say that all logicians are pendants. When we speak of words or sentences as true, this is elliptical for what is said when we use them. Indeed, even those who postulate other truth-bearers often acknowledge that we actually use 'true' in this way.'

It might be objected that the metaphysical nature of truth cannot be determined by reference to how we use 'true' and its cognates. But it is hard to see how our concept of truth-the subject of the debate-could be completely independent of how we explain and use 'true' and its cognates. Could it turn out, for example, that, the ordinary use of non-philosophical philistines notwithstanding, truths are actually a species of Amazonian termites? On what grounds can we rule out that suggestion, or a serious proposal like mentalism, if not by reference to what it makes sense to say about truths, e.g. that they cannot crawl but can be communicated? Nor can my points be dismissed as concerning only the superficial or pragmatic aspects of our use of 'true'. If any feature of 38-9. 


\section{Hans-Johann Glock}

that use has semantic significance, it is that we apply 'true' to thatclauses rather than quoted sentences, and the way in which we individuate truths.

However, there is a more sophisticated version of this objection. One might hold that like epistemic concepts, 'it does not make sense to say' creates an intensional context, and is therefore no obstacle to a metaphysical thesis about identity. That it does not make sense to say things about truths which it does make sense to say about sentences does not show that truths are not identical with sentences. Although we apply different terms to a truth on the one hand, a sentence on the other, the thing to which we apply them might be one and the same. This position is particularly attractive if one sticks to tokens rather than types, since it would allow one to combine a conceptual pluralism with an ontological monism, the idea that the reality to which we apply our diverse idioms is physical. Our alethic vocabulary picks out a part of physical reality (token-sentences), but does so in a non-physical manner, just as, according to Davidson's anomalous monism, our mental vocabulary picks out brain-states in an irreducibly mental manner.

I shall argue that there is a kernel of truth in this response: truths are not part of a reality beyond the physical world. However, it is doubtful whether it rehabilitates sentences as truthbearers. For one thing, it is far from obvious that what it makes sense to say does create an intensional context. 'It makes no sense to say that the central truth of the theory of relativity is $2 \mathrm{~cm}$ long' and 'That $\mathrm{E}=\mathrm{mc}^{2}$ is the central truth of the theory of relativity' seem to entail 'It makes no sense to say that that $\mathrm{E}=\mathrm{mc}^{2}$ is $2 \mathrm{~cm}$ long'. In any event, this defence concedes that, alleged ontological identities notwithstanding, our concept of a truth differs from our concept of a sentence (whether types, tokens, or eternal types) in what it applies to and in its criteria of identity.

\section{Unbearable Truth-Bearers: Platonism}

Many philosophers have reacted to the shortcomings of nominalism by adopting a Platonist account of truth. According to that position, truths are self-subsistent abstract entities which exist eternally in a separate ontological realm beyond space and time; moreover, although our sentences express to such entities, these entities need not be understood, believed or stated by human beings; if they are, this is a further fact which is extrinsic to their existence. 


\section{Truth Without People?}

Given the ontological divide it postulates between the material and the abstract realm, Platonism has great, if not insurmountable, difficulties in explaining this fact. Moreover, Platonism can be accused of replacing a puzzle-what distinguishes a truth from a sentence-by a mystery - the idea of a super-natural world beyond space and time to which we have access by some kind of 'intellectual intuition'. It treats truths as objects which are just like mountains, only without any spatial, temporal or causal properties; similarly, our grasp of truths is treated as a kind of perception, which is just like ordinary perception, only not sensible. But these qualifications, many have felt, lead us directly from the familiar to the irredeemably mysterious.

It might be replied that both parts of this 'just like..., only...' move are justified. Just like mountains, truths are objects in that they are grammatical subjects to which we refer by noun-phrases. Just like mountains, truths are not created or destroyed by people thinking or saying things. Unlike mountains, truths cannot be located in space and time, or be part of causal chains.

In some respects, this reply is correct. Platonism is right to insist on the non-physical yet objective nature of truth. However, Platonism does not simply note important logical features of thatclauses or 'true'. It tries to explain these features by conceiving of truths as self-subsistent entities of an ethereal kind. As a result, it misconstrues these logical features. Not all grammatical subjects are objects; not all noun-phrases are names of objects. This has long since been recognized in cases like 'everything' and 'nothing'. But it holds equally of, e.g., 'the North' or 'the past', which are noun-phrases without referring to objects in even the most catholic sense of that term. Furthermore, like truths, the past cannot be altered by what people do or say. Being objective does not entail being an object. Platonism puts a metaphorical ontological gloss on logical truisms, and thereby fails to do justice to the explananda.

One of these truisms is that while it makes sense to apply spatial and temporal terms to sayings, it does not make sense to apply them to what we say-truths and falsehoods. The truth that Hastings was fought in 1066 is located neither on the battle-field, nor in 1066. Platonism seems to take this point on board, but its metaphors actually militate against it. For it follows that the question 'Where are truths and falsehoods located?' should be rejected as based on a misunderstanding. Instead, Platonism answers that question by imputing a non-spatial sense to 'where' and saying, for example, that they are located in a 'third realm' beyond space. Equally, Platonism seems to accept that temporal terms do not 


\section{Hans-Johann Glock}

apply to truths. Yet at the same time it regards them as 'eternal', which means that they exist from the beginning to the end of time. But concepts of duration are no more licit here than concepts of temporal location. For example, it is not the case that the statement 'Children worked in the mines in England in the eighteenth century' ceased to be true, although it ceased to be true of England that children worked in its mines. ${ }^{10}$ Truths and falsehoods are not eternal or everlasting, as the Platonist metaphor suggests, they are timeless or atemporal. It is not that statements are true at all times; rather, the idea of being true at a time makes no sense.

By a similar token, Platonism is right to reject the idea that the truth that there are radioactive substances was brought into existence around 1900, when people started believing and stating it, or that it could be destroyed by people stopping to do so. However, that truths are not the sort of things which can begin or cease to exist does not mean that they are things which are immune to change because they abide in a world beyond the causal order. To express the mind-independence or objectivity of truth by stating, e.g.,

(3) Before 1900 , there was a truth that there are radioactive substances

is infelicitous, and so is even the more acceptable

(3') It was a truth before 1900 that there are radioactive substances.

What can be said is

(3*) It is a truth that there were radioactive substances before 1900.

And that in turn is logically equivalent to

(3\#) There were radioactive substances before 1900.

In trying to defend the objectivity of truth against mentalism and nominalism, Platonism misconstrues it. That (3\#) is true irrespectively of our thinking or saying so has nothing to do with the alleged eternal existence of an entity in the abstract realm, but everything with the fact that, with certain exceptions (e.g. the statement that someone is talking), our saying that $p$ does not make it the case that $p$. The objectivity of truth boils down to the conceptual truism that ' $p$ ' and 'People believe/think/state/say that $p$ ' do not entail each other.

By a similar token, that different people can think the same thought or hold the same belief does not mean that there is an

${ }^{10}$ Cf. A White, Truth (London: Macmillan, 1970), pp. 24-7. 


\section{Truth Without People?}

abstract object to which they severally stand in the relation of thinking, believing, saying. It just means that both $\mathrm{A}$ and $\mathrm{B}$ believe that snow is white; that is to say, what they both believe is expressed by the same that-clause. If we are to disagree, what I say or assert must be what you deny. But this does not commit one to the existence of entities beyond space and time, only to the conceptual truism that if I deny what you assert, and you assert that $p$, then I deny that $p$.

However, one might jettison the metaphorical talk of ethereal and eternal objects beyond space and time, while insisting that truths are abstract objects rather than mental or material ones. The problem with this austere version of Platonism is that the analogy between concrete and abstract objects is 'strictly limited and purely logical': they all are topics of speech or subjects of predication. "In the case of truths or propositions, the analogy is even thinner than in the much debated case of numbers.

To be sure, propositional- or that-clauses can function grammatically as an accusative. But they are intentional rather than object-accusatives; that is to say, they do not specify something which needs to exist for the statement to be true. In 'A believes B', ' $B$ ' is an object-accusative; it must refer for the statement to be true. By contrast, in 'A believes that $p$ ', we do not need two relata-one to believe and one to be believed. When A believes falsely that $p$, then it is not case that $p$; there is no actual fact to which 'that $p$ ' refers. But that is no threat to A having the belief that $p .{ }^{12}$

Next, it seems that we can refer to what is said, stated or believed by that-clauses, and predicate certain things of it, e.g. that it is implausible, wonderful, unexpected, etc. In some cases we

"Strawson, Logico-Linguistic Papers, p. 74.

${ }^{12}$ See A. White, 'What we Believe', in N. Rescher (ed.), Studies in the Philosophy of Mind (Oxford: Blackwell, 1972); P.M.S. Hacker, 'Malcolm and Searle on Intentional States', Philosophical Investigations 15 (1992).

This distinction cannot be dismissed by invoking examples from fictional discourse, since in these cases $\mathrm{A}$ and $\mathrm{B}$ must both exist in the fictional world for 'A believes B' to be true.

In the spirit of the Tractatus, it might be replied, however, that even in the case of 'A believes that $p$ ', there must exist a possible fact. But this boils down to saying that ' $p$ ' is a meaningful declarative sentence which is either true or false, depending on how things are. It does not affirm the existence of an object which is isomorphic with an actual fact, only less tangible. The postulation of such an intermediary between A's belief and the world implies that what A believes is one thing-a fact-if it is true that $p$, but another-a possible fact-if it is false that $p$; but what A believes must be the same in both cases. See my $A$ Wittgenstein Dictionary (Oxford: Blackwell, 1996), 'intentionality'. 


\section{Hans-Johann Glock}

even have names for what is said (the Pythagorean theorem, Newton's second law, Tractatus 3.5), which are substitutable salva veritate for the corresponding propositional clauses, e.g. 'Newton's second law is true' and 'that $\mathrm{F}=\mathrm{ma}$ is true'.

But what is said is not like what is eaten (a cake). The word 'what' introduces a propositional clause, not the name of a thing. We say (believe/judge) that such-and-such is the case. The thatclause does not have the function of introducing an object. Contrast 'Mary Robinson is wonderful' with 'That communism collapsed is wonderful'. In the former case, there is a thing or person which has the quality of being wonderful. In the latter cases, there is no such thing or person: what is wonderful is not an object, but that communism collapsed. It might be replied that what is wonderful here is a fact. But a fact is no more an object than a truth; indeed, the two concepts are intimately connected. Like truths, facts are expressed by that-clauses, and are not located in space and time. Like the truth that Hastings was fought in 1066, the fact is neither here nor there, neither now nor then.

Nor can it be argued that propositional clauses must refer to objects of some kind, since some of them are co-referential with names. While we can substitute co-referential expressions salva significatione even in intensional contexts, we cannot do so in the case of that-clauses and names of propositions: 'that $p$ is my belief' is well-formed, but 'the theorem/proposition is my belief' is not; I can have heard of Newton's second law, but not of that $\mathrm{F}=\mathrm{ma}$.

It may seem, however, that propositional clauses can occur to the left and right of the identity-sign, which is often taken to be a hallmark of referring expressions. But a statement like 'Newton's second law is that $\mathrm{F}=$ ma' is less common and perspicuous than 'Newton's second law is: $F=$ ma'. In these latter cases, the clause to the right of 'is' does not refer to Newton's second law, it states or expresses it. This is part and parcel of the fact that in most contexts, propositional clauses are eliminable without change of sense or truth-value: 'A believes that $\mathrm{F}=$ ma' $\equiv$ 'A believes $\mathrm{F}$ to equal ma'; 'A expects that B will come' $\equiv$ 'A expects B to come'; 'A suspects that there is foul play' $\equiv$ 'A suspects foul play'; 'The cleverest thing A ever said was that $p$ ' $\equiv$ 'A said that $p$, and A never said anything as clever as that $p$ '. In these cases, the only things referred to are $\mathrm{B}, \mathrm{A}$, and what $\mathrm{A}$ said. Combined with the negative points, this suggests that while propositional clauses are nounphrases, their function differs from that of other referring expressions. By the same token, what is true or false, what is said or believed is not an object, entity or thing; it does not exist or obtain 
in either the material world, as nominalism has it, or the abstract realm postulated by Platonism.

\section{What People Say and the Concept of Truth}

Both nominalism and Platonism are among the sturdiest of philosophical paradigms. The above arguments do purport not to refute them, but only to provide arguments for avoiding both alternatives. Where do they leave anthropocentrism? They rule out an obvious justification of

$\left(1^{\prime}\right)$ If there were no people, there would be no bearers of truth

namely that without people there would be no bearers of truth and falsity since there would be no sentences, albeit not on grounds of excessive anti-realism. However, both Davidson and Wittgenstein intimate a different rationale for $\left(1^{\prime}\right)$, and one which is in line with our argument.

Wittgenstein insists that what is true or false is what people say, which is neither the act of saying, nor the tokens of types which are used to say it. Davidson's position involves the idea that 'true' applies to sentences. But he also suggests that it applies to types of utterances and inscriptions, where a type is not just an acoustic or typographic class, but comprises all utterances and inscriptions with the same truth-conditions, and hence tokens of different types, e.g. 'Schnee ist weiß' and 'Snow is white' ('The Structure and Content of Truth', p. 209). On both counts, it seems, (1') would hold. Without people or speakers, nothing would be said, no utterances or inscriptions would be made; hence there could be nothing for the concepts of truth and falsity to apply to.

At first sight, it may appear as if this argument rests on the idea that the concepts of truth or falsity apply exclusively to what people actually say or write. This would be fatal, since there are true thoughts which have never been expressed. However, both Davidson and Wittgenstein recognize this point, which is why they link truth to 'thinking', or 'thinking creatures'. This does not affect their case against realism. $\left(1^{\prime}\right)$ is independent of any claim about the relationship between thought and language. Without people, there could be neither true statements nor true thoughts.

Another problem remains. There are not just true thoughts which no one has ever expressed, but also truths which no one has ever entertained, even in silence. Once more, Davidson and Wittgenstein are alive to this possibility. Thus Davidson stresses that sentences in his sense are not confined to types of utterances 


\section{Hans-Johann Glock}

that have been realized, but comprises types which have not. Equally, Wittgenstein's dictum is easily modified to read: true or false is what people say or could say.

The real problem for anthropocentrism is whether this concession is compatible with $\left(1^{\prime}\right)$. Given that a bearer of truth is a truth, $\left(1^{\prime}\right)$ implies

(1*) If there were no people, there would be no truths.

But if there are truths no one has ever believed, there seems no reason to reject

(4) If there were no people, there would still be truths.

In any event, (4) seems required on pain of idealism. To reject

(2) If there were no people, there would be no mountains is to accept

$\left(4^{\prime}\right)$ If there were no people, there would still be mountains.

This in turn implies

(4*) If there were no people, it would still be true that there are mountains.

(4*) in turn seems to imply

(4\#) If there were no people, it would still be a truth that there are mountains.

which itself implies (4).

Rorty has recently questioned the move from $\left(4^{\prime}\right)$ to $\left(4^{*}\right)$. 'What is "be true" supposed to mean in a world in which there are no statements to be true nor minds to have true beliefs?" ${ }^{13}$ According to Rorty, the realist cannot reply to this question without dogmatically presupposing his account of truth, and hence the dispute between him and his opponent hinges on incommensurable metaphysical attitudes. But this conclusion is precipitate. Rorty's challenge to the realist runs together the question of what 'is true' means in a world without people with the question of what it means of a world without people.

There is a strong case for holding that the phrase 'is true' would not mean anything in a world in which there are no people to use it. This case is of a piece with the conceptualist view that words

13 'Just one more Species doing its Best', London Review of Books 25.07.91, p. 3; see also his 'Representation, Social Practice, and Truth', Philosophical Studies xxx (1988). 
have meaning (and hence express a concept) not by virtue of being associated with a self-subsistent abstract entity, but by virtue of being explained and employed. In a world without people, ex hypothesis, no one would be in a position to explain the expression 'is true', or to use it in statements like (4*). It would follow that 'is true' would be meaningless in such circumstances.

But this does not entail that we cannot meaningfully use 'is true' to make a statement such as $\left(4^{*}\right)$. We can specify what such a statement amounts to without begging the question in favour of realism. 'It is true that there are mountains' means the same of a world without people as it does of a world with people, namely simply that there are mountains. This equivalence does not rely on any realist or Platonist assumptions. In particular it does not presuppose a correspondence theory of truth according to which truth is a relation between a thought or proposition and a mind or language-independent item, a fact. On the contrary, the equivalence is essential to the deflationary account of truth which Rorty himself favours. Such deflationary accounts deny that truth involves a metaphysical relation between thought and reality, on the grounds that there is nothing more to the concept than equivalences like 'It is true that $p$ if and only if $p$ ' or (as Rorty, being a nominalist, would put it) ' $p$ " is true if and only if $p$ '. So, if Rorty is right to hold a deflationary account of truth, his argument against realism fails. More importantly, whether or not a deflationary account of truth is adequate, the equivalence itself is a truism, on a par with Aristotle's famous observation that to say of what is that it is, is true.

Does that mean that $\left(1^{\prime}\right)$ and $\left(1^{*}\right)$ are simply false, irrespective of the merits of Platonism? One might resist that conclusion by employing against the realist the very distinction I used against Rorty. Even if there were no people, it would still be true that there are mountains, radioactive substances, etc. But all that means is that there are truths of a world without people, but not that there are truths in a world without people. Unless one endorses Platonism, one has to admit that in such a world there would indeed be nothing-no thing-to which one could apply 'true', because there would be no statements, assertions, theories, etc. To be sure, what is true and false is not just what is actually said, but what could be said. But while many things can be said of a world without people, there is nothing which can be said in such a world, because, ex hypothesis, there is no one to say it.

There is a kernel of truth in this argument. Barring Platonism, truths are not abstract entities which exist in a world without people because they are unaffected by the disappearance of humans thinking or expressing them. Nevertheless, we can say what holds 


\section{Hans-Johann Glock}

true in a world without people no less than we can say what holds true of such a world. The crucial point is that what holds true in or of both the actual and the fictional world, e.g. that there are mountains, is not a kind of object. Propositional clauses do not name objects of any kind, material, mental, or abstract, actual or possible. That there are mountains is not a thing in either the fictional or the actual world. Rather, it holds true of the actual world and would hold true of the fictional world.

Anthropocentrism should challenge not (4') itself, as Rorty does, but the move to (4\#), and thereby to (4). These statements are not so much false as misleading, in that they speak of the existence of truths or of there being such-and such a truth. This suggests that truths are objects which are either created and destroyed at a certain time, as some anthropocentrics suggests, or exist eternally, irrespective of what people say and do, as realism has it. But truths are not things which can begin to exist, cease to exist, or last for ever.

Both realism and anthropocentrism are confused in so far as they make their debate turn on the existence and longevity of certain entities. At the same time, both contain important kernels of truth. Platonism is right to point out the difference between a saying and what is said. Anthropocentrism is right in insisting that what is said is not an abstract entity which exists separately from the utterance or inscription. It is distinct from the utterance only in the sense in which, e.g., a pound is distinct from a pound note. The note does not name a pound, but to present the note is to present a pound. Equally, the utterance does not name an abstract entity (proposition), but to make the utterance in the appropriate circumstances is to say something, is to utter a truth or falsehood. To speak of what is said by different token-sentences, or to insist that different token-sentences can say the same thing, is not to relate them to a single abstract entity. Instead, it is to group or classify actual or potential token-sentences in a certain way, namely according to what, given our linguistic rules, they say or can be used to say. 'We are talking about the spatial and temporal phenomenon of language, not about some non-spatial non-phantasm. Only it is possible to be interested in a phenomenon in a variety of ways. ${ }^{14}$

Although truths are not themselves linguistic acts or their products, anthropocentrism is right to regard them not as self-subsistent objects, but as what Prior called logical constructions from linguistic phenomena, namely from the that-clauses by which we report and refer to what people say. ${ }^{15}$ The criteria of identity for

${ }^{14}$ Philosophical Investigations, $\$ 108$; a similar view seems implicit in Davidson, Inquiries, pp. 43-5.

${ }^{15}$ Objects of Thought (Clarendon Press, Oxford, 1971), ch. 2. 
truths make essential references to linguistic acts (sayings or utterances). There are truths no one has ever uttered or thought of. But what distinguishes two such truths is evident from the declarative sentences which express them. Although our criteria of identity for truths and falsehoods are not the same as our criteria of identity for sentences, we can only identify the former because we can identify the latter. Although there are different linguistic expressions for the most important truth discovered by Newton and the most important truth discovered by Einstein, what distinguishes these two truths is evident from their expressions-' $F=$ ma' and ' $\mathrm{E}=\mathrm{mc}^{2}$ '.

This line of thought does not support $\left(1^{\prime}\right)$ or $\left(1^{*}\right)$, the claim that truths would go out of existence in the absence of people, or impugn (4*), the claim that even in the absence of people it would be true that there are mountains, etc. Instead, it suggests that it makes sense to speak of unentertained or unexpressed truths only because there are truths which people do entertain and express. Nor is this simply due to the need to explain 'unentertained' and 'unexpressed' by reference to their opposites. The deeper rationale is that without implicit reference to the idea of people saying things, we can explain neither what 'is true' applies to, nor what distinguishes different truths.

Instead of discoveries about the existence of truths, this argument reveals something about the concept of truth. One cannot have the concept of truth without having the concept of a sentence, hence the concept of a language, and hence the concept of languageusers. ${ }^{16}$ This does not establish that there cannot be truths without people. One cannot have the biological concept of a fruit without having the concept of a seed, but that does not show that there cannot be fruits without seeds. However, if I am right, the analogy does not hold. It is misleading to claim either that there can or that there cannot be truths without people; for, unlike fruits, truths are not objects. But although my argument concerns the concept of truth, it does not boil down to the conceptualist claim that, like any other concept, that of truth owes its existence to the activities of people. It expresses a new rationale for denying that there is a concept of truth in the absence of people, one which does not apply to all concepts. The notion of what people say or can say is essential to the concept of truth but not to other concepts. Without reference to what people say or can say it cannot be explained what 'true' applies to, or what distinguishes one truth from another.

${ }^{16}$ The argument is the reverse of, but compatible with, Davidson's idea that one cannot have the concept of a language without the concept of truth. 
Both claims presuppose that even truths which have never been stated or entertained must be capable of being stated, at least in principle. It must be logically possible to formulate such truths. A determined realist might reject this assumption. However, to hold that there are truths which are essentially inexpressible is not to reject anti-realism, it is to condone a severe form of mysticism. This mysticism is stronger than Platonism, since it is possible to hold that thoughts are self-subsistent entities, while insisting (with Frege) that they must be capable of being expressed. Finally, 'ordinary' mystics maintain only that people have ineffable experiences (notably of a religious kind), that is, experiences which forever defy any attempts to articulate or elucidate them. Our realist mystic, by contrast, cannot even invoke ineffable experiences, since mention of experiences brings in people. If realism can only be salvaged by this kind of mysticism, it is less down to earth than it likes to appear.

Finally, the realist might argue that even if it is an essential property of truths to be effable, this does not make them anthropocentric. For it is also an essential property of stones to be kickable. But while kickability and assertability are anthropocentric properties, stones are not anthropocentric objects, and hence neither need be truths. However, the analogy breaks down at the crucial point. Being kickable is not a defining feature of stones: we can explain what stones are without any mention of it. By contrast, if I am right, we can explain neither what truths are, nor what their criteria of identity are, without reference to the linguistic expressions of truths.

My conclusion is therefore that there are three qualifications to the realist thesis that the concept of truth is absolutely independent of people which do not imply discredited anti-realisms: the concept of truth would not exist without people capable of calling some things true and others false; it is only possibly to state what the bearers of truth and falsity are in terms which implicitly refer to what people say; and we identify truths and falsehoods by grouping or classifying actual or potential token-sentences according to what they say. Put loosely, sentences, although they are not the bearers of truth, are the vehicles of truth, and language is its medium. ${ }^{17}$

\section{Department of Philosophy, University of Reading}

17 This paper arose out of a presentation at the St. John's College Discussion Group; a more polished version was delivered to the Work in Progress forum at Reading and at Keele. I am grateful for the feedback provided by these groups, and for comments by John Cottingham, Peter Hacker, Brad Hooker and John Hyman. 